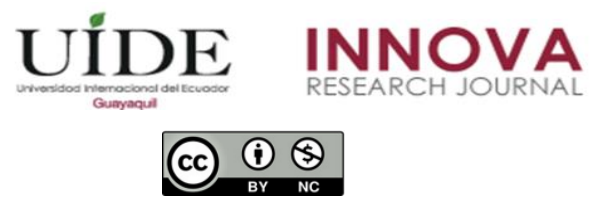

INNOVA Research Journal, ISSN 2477-9024

(Enero-Abril 2020). Vol. 5, No.1 pp. 242-254

DOI: $\underline{\text { https://doi.org/10.33890/innova.v5.n1.2020.1045 }}$

URL: http://revistas.uide.edu.ec/index.php/innova/index

Correo: innova@uide.edu.ec

\title{
Turismo ornitológico en los humedales de Lima 2019
}

\section{Ornithological tourism in the wetlands of Lima 2019}

Eduardo Pablo Vivanco Calderon

Universidad Norbert Wiener, Perú

Autor para correspondencia: pablo_vivanco@hotmail.com.

Fecha de recepción: 08 de julio del 2019 - Fecha de aceptación: 09 de enero del 2020

\section{Resumen}

La presente investigación tiene como objetivo diseñar un plan para promocionar el desarrollo del turismo ornitológico en los humedales de Lima, para ello se tomó en cuenta los Pantanos de Villa y los humedales de Ventanilla ya que son dos humedales importantes para el desarrollo del turismo ornitológico. Se utilizó una metodología con sintagma holístico y enfoque mixto utilizando instrumentos cuantitativos y cualitativos, es de tipo proyectivo y de nivel comprensivo. La muestra estuvo constituida por sesenta visitantes y tres trabajadores. Según los resultados, se destaca la falta de inversión en infraestructura en los humedales, también carecen de tecnología para realizar este tipo de turismo, falta implementar programas de educación ambiental dirigido a pobladores, escolares y visitantes para fomentar la conservación de los humedales, también se observa la falta de información y promoción del turismo ornitológico ya que es un turismo poco conocido pero que ayudará en la sostenibilidad de los humedales. Como alternativa de solución se planteó promocionar el turismo ornitológico en los colegios de Lima mediante charlas y realizando la actividad ornitológica en los humedales. Se diseñó la mejora de infraestructura en los humedales y una estrategia para promocionar la actividad mediante las redes sociales.

Palabras claves: promoción; turismo ornitológico; humedales; sostenibilidad; educación ambiental

\begin{abstract}
The present research work aims to propose an ornithological tourism promotion plan in the wetlands of Lima, for the study was considered the Pantanos of Villa wetlands and Ventanilla wetlands. The research had a holistic methodology and a mixed approach, techniques and instruments were used quantitative and qualitative, with type of projective research and comprehensive level. The sample it was constituted by sixty tourists and three workers. According to the result there is a lack of investment in infrastructure in the wetlands, lack of technology, environmental education programs must be implemented directed to inhabitants, school children and visitors for the conservation and sustainability of wetlands, it is also observed lack of information and promotion the ornithological tourism, it is a type of ecotourism unknown but it is help in the sustainability of wetlands. As one alternative solution it was proposed to promote the ornithological tourism in the school of Lima through talks and doing the
\end{abstract}


ornithological activity in the wetlands, for it one strategy to improve the infrastructure in the wetlands and one strategy to promote the activity through social networks.

Key words: promotion; ornithological tourism; wetlands; sustainability; environmental education

\section{Introducción}

El turismo es una actividad que genera desarrollo tanto a nivel social, cultural y económico beneficiando directamente a los pobladores gracias a los ingresos económicos que se pueden obtener, por ello en la actualidad es un sector económico importante para cada país. El turismo se ha diversificado gracias al incremento de la demanda, y los cambios en la preferencias y tendencias de los turistas, es por ello que este sector ha incrementado en todo el mundo, incluso negocios turísticos, igualan a negocios petroleros, de alimentación y automovilísticos. (Organización Mundial del Turismo, 2018).

El turismo en el Perú hoy en día es considerado política de estado ya que hoy en día es una actividad importante en el país, en los últimos años se ha relacionado al turismo con el medio ambiente debido a las nuevas experiencias que desean obtener los turistas. (Plan Estratégico nacional de Turismo, 2018).

La OMT promueve el turismo como la nueva economía verde ya que se considera como un sector que genera crecimiento nacional, es por ello que se debe diversificar los productos turísticos que respondan de los turistas. (OMT, 2011).

Según el perfil vacacional 2017 se puede observar que el 56\% de turistas tienden a realizar turismo de aventura y naturaleza, donde el avistamiento de aves es uno de los más solicitados debido a que el Perú cuenta con mil ochocientas treinta especies de aves indicado en la lista oficial del SACC / CRAP siendo el segundo país con mayor biodiversidad en todo el planeta. (PROMPERU, 2017).

Lima cuenta con humedales, los cuales son áreas cuyo componente principal es el agua dando vida a la diversidad d flora y fauna y se hallan donde la superficie está cubierta por aguas no profundas, siendo extensiones que pueden ser temporales o permanentes, estancados o corrientes, dulces y saladas; los cuales son un fuerte potencial para la práctica del turismo ornitológico ya que son áreas importantes del corredor biológico de aves migratorias del pacifico del sur. (Ramsar, 2006).

Los humedales son áreas naturales donde se puede encontrar importante biodiversidad flora y fauna, es por ello que se debe fomentar hábitos y prácticas sostenibles para su conservación, a la vez tiene alto potencial de uso educativo, científico y turístico.

La presente investigación se realizó en los Pantanos de Villa y en los humedales de Ventanilla, con la finalidad de estudiar y tener de referencia el cómo se está desarrollando la actividad turística ornitológica en los humedales de lima y conocer el estado actual de los humedales, en los cuales se puede observar que no cuentan con una infraestructura turística exclusiva para realizar el turismo ornitológico y que brinden comodidad al turista, también se 
observa que no existe mucha información del turismo ornitológico, es por ello que los visitantes realizan otros tipos de actividades en los humedales siendo pocos los que realizan turismo ornitológico, es por ello que es fundamental plantear una propuesta para fomentar el turismo ornitológico en los humedales, generando beneficios a los pobladores, a la vez crear sensibilidad y fomentar el uso de prácticas sostenibles para conservar el área natural.

Para ello se revisó la teoría de la sostenibilidad, donde se analiza que a través de la participación de políticos y ciudadanos se puede obtener el desarrollo económico y social a través de la conservación ambiental (Brundtland 1987), también se tomó en cuenta la teoría del espacio turístico según Boullon el cual indica que la actividad turística trabaja sobre espacios determinados denominados atractivos turísticos donde el hombre crea estructuras donde los organismos que habitan se puedan adaptar sin perjudicar los ecosistemas existentes (Boullon, 2006).

A nivel nacional Bohorquez (2017) analizó si el turismo ornitológico que se realiza en los "Humedales de Ite", genera sensibilización ambiental de los pobladores del distrito de Ite, mientras que Criales (2016) realizó la propuesta de un modelo de gestión para mejorar la infraestructura turística en los Humedales de la Costa Central (HCC) del Perú. A nivel internacional Hernández (2017) analizó si el turismo de avistamiento de aves es un producto turístico en Bogotá región para ver sus posibilidades de desarrollo finalmente Altamirano (2015) diseñó puntos estratégicos para el avistamiento de aves que faciliten el aviturismo dentro de la isla Santay.

Se debe entender que el turismo ornitológico es aquel viaje cuya motivación es poder realizar actividades que permitan relacionarse con la ornitología, como la observación de avifauna, con el fin de conocer las áreas naturales y cubrir sus expectativas de aprender y tomar conciencia de la naturaleza. López (2008) En la presente investigación se desea fomentar el turismo ornitológico en los humedales de Lima para fomentar la sostenibilidad a través de la educación ambiental, se desea concientizar a los entes involucrados en la conservación de las áreas naturales, de esta manera los humedales podrán ser productos turísticos que se puedan ofrecer a los turistas.

Para la siguiente investigación se consideró como sub categorías ejes del presente estudio las siguientes:

Infraestructura turística, son los elementos básicos para el funcionamiento de un atractivo turístico, la existencia de la infraestructura es vital para que se pueda desarrollar el turismo. Para que el turismo ornitológico, pueda realizarse con normalidad y ser del agrado del turista, es necesario planificar y gestionar una infraestructura que permita adaptar los recursos para el desarrollo de la actividad sin generar impactos en los ecosistemas. (MINCETUR 2011).

Rutas turísticas, puede ser un circuito o recorrido turístico con un concepto temático establecido adquirido a través del atractivo o lugar de interés que lo componen. Para poder realizar el turismo ornitológico es necesario que se establezca una ruta turística planificada en conjunto con una infraestructura definida para que se pueda realizar el recorrido, el acceso del atractivo debe tener las facilidades para la llegada de los turistas. (MINCETUR 2011). 
Beneficio para la localidad, los humedales son áreas donde el agua tiene una función importante, dando vida a una diversidad de flora y fauna, son extensiones que pueden estar de manera temporal o permanente, estancados o corrientes, dulces o saladas. Los humedales son áreas naturales importantes para mantener la biodiversidad de flora y fauna del planeta. (Ramsar 2006). En los humedales se puede desarrollar el turismo ornitológico debido a que por temporadas se pueden observar aves migratorias, siendo un producto para los turistas que tienen afinidad por las aves, teniendo como consecuencia el beneficio económico y social de los pobladores de la zona, promoviendo la conservación de los humedales.

Conservación de la biodiversidad, La biodiversidad turística es aquel lugar formado por una diversidad de genes, especies y ecosistemas, conformando un sistema de materia orgánica e inorgánica apoyado por una coacción de la naturaleza donde interactúan y cambian constantemente. Conservar un espacio natural, es el ejercicio de mantenerlo en buen estado a través de actividades planificadas con la finalidad de aprovechar su uso de manera sostenible en beneficio a la actividad turística. (Figueroa 2003).

Flujo ecoturístico, se define el ecoturismo como la forma de turismo basado en la naturaleza cuyo interés del turista es familiarizarse con la naturaleza o culturas tradicionales que existe en la zona natural. El flujo ecoturístico es denominado el porcentaje de turistas que visitan un determinado lugar, el cual genera la demanda turística, la cual es objeto de estudio por las empresas de turismo para ofrecer diversos productos turísticos. (Organización mundial del turismo, 2002).

El objetivo general fue proponer un plan de desarrollo para fomentar el turismo ornitológico en los humedales de Lima; mientras los objetivos específicos fueron: Analizar o diagnosticar cómo se desarrolla el turismo ornitológico en Lima, teniendo en cuenta el estudio en los humedales de Pantanos de Villa y los humedales de Ventanilla en el 2019 y explicar los factores y causas de mayor incidencia en la gestión del turismo ornitológico en los humedales de Lima según el estudio en Pantanos de Villa y los humedales de Ventanilla en el 2019.

\section{Materiales y Métodos}

El presente estudio se realizó con un enfoque mixto usando herramientas e instrumentos cuantitativos y cualitativos, para determinar la problemática del estudio. Se trabajó en función del sintagma holístico, con un tipo de investigación proyectiva porque se elaboró una propuesta de plan, con una categoría problema a la cual se le dará soluciones de manera práctica (Hurtado, 2000). Se obtuvo dos categorías en el presente estudio el primero fue la observación de aves y el segundo fue el desarrollo ecoturístico y las sub categorías: Infraestructura, rutas de avistamiento de aves, beneficios para la localidad, conservación de la biodiversidad y flujo ecoturístico. Se trabajó con una muestra cuantitativa de 60 visitantes de los humedales, para ello se utilizó encuestas tipo Likert con validez y confiabilidad. Así mismo, se realizó el análisis cualitativo a partir de entrevistas a 3 trabajadores de los humedales que conocen la zona en estudio. En el procesamiento de información, resultados estadísticos y triangulación se utilizó en programa SPSS y el Atlas ti. 


\section{Resultados}

Según los datos cuantitativos que se han procesado encontramos que en infraestructura el $43.33 \%$ de los encuestados indican que el humedal a veces cuenta con una infraestructura adecuada para realizar el turismo de avistamiento de aves, pero no en todo el humedal, también un $43.33 \%$ indica que normalmente la infraestructura puede generar impacto negativo, un $45 \%$ considera que a veces la infraestructura cuenta con la tecnología necesaria para realizar el turismo de avistamiento de aves, también se observa que un $33.33 \%$ considera que los entes involucrados como los gobiernos regionales y locales a veces invierten en infraestructura. Según los resultados de las encuestas podemos apreciar que la subcategoría de infraestructura no se ha aplicado como debería de ser en los humedales hay una falta de planificación e inversión para que se pueda desarrollar el turismo de avistamiento de aves sin ningún problema para los turistas.

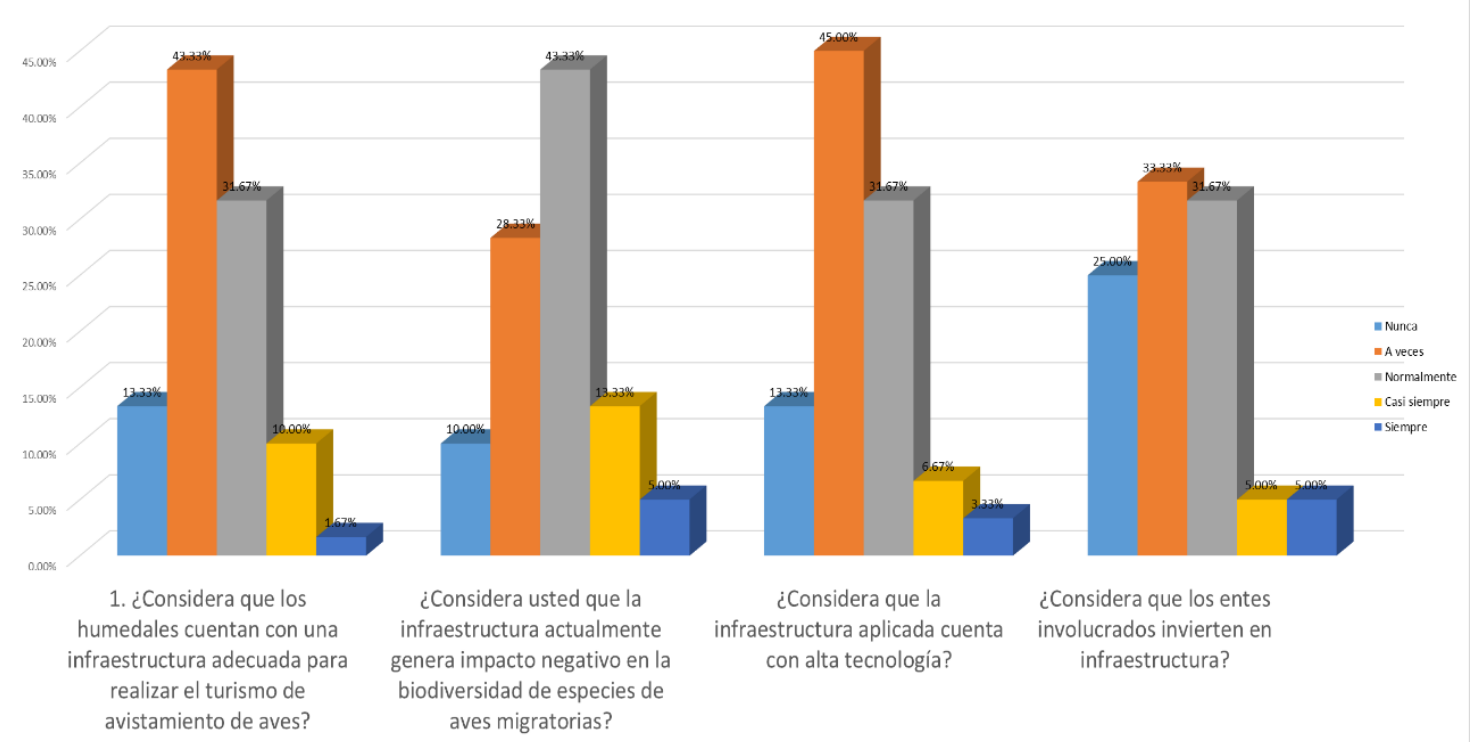

Figura 1. Frecuencias y porcentajes de los ítems correspondientes a la subcategoría Infraestructura para el desarrollo del turismo de avistamiento de aves en los humedales de Lima 2019

En la subcategoría rutas de avistamiento de aves encontramos que el $45.00 \%$ de los encuestados indican que en los humedales normalmente las rutas de acceso y equipamiento son las adecuada y se encuentran en buenas condiciones para realizar el turismo de avistamiento de aves, un $31.67 \%$ considera que casi siempre existe señalización en todo el humedal, un 58.33\% $\%$ considera que casi siempre existe guiado turístico en los humedales, y un $33.33 \%$ considera que se brinda servicios turísticos. Según los resultados de las encuestas podemos apreciar que la subcategoría rutas de avistamiento de aves existe señalización dentro de los humedales, existe guiado turístico, normalmente hay servicios turísticos, pero que las rutas de acceso si se debe mejorar. 


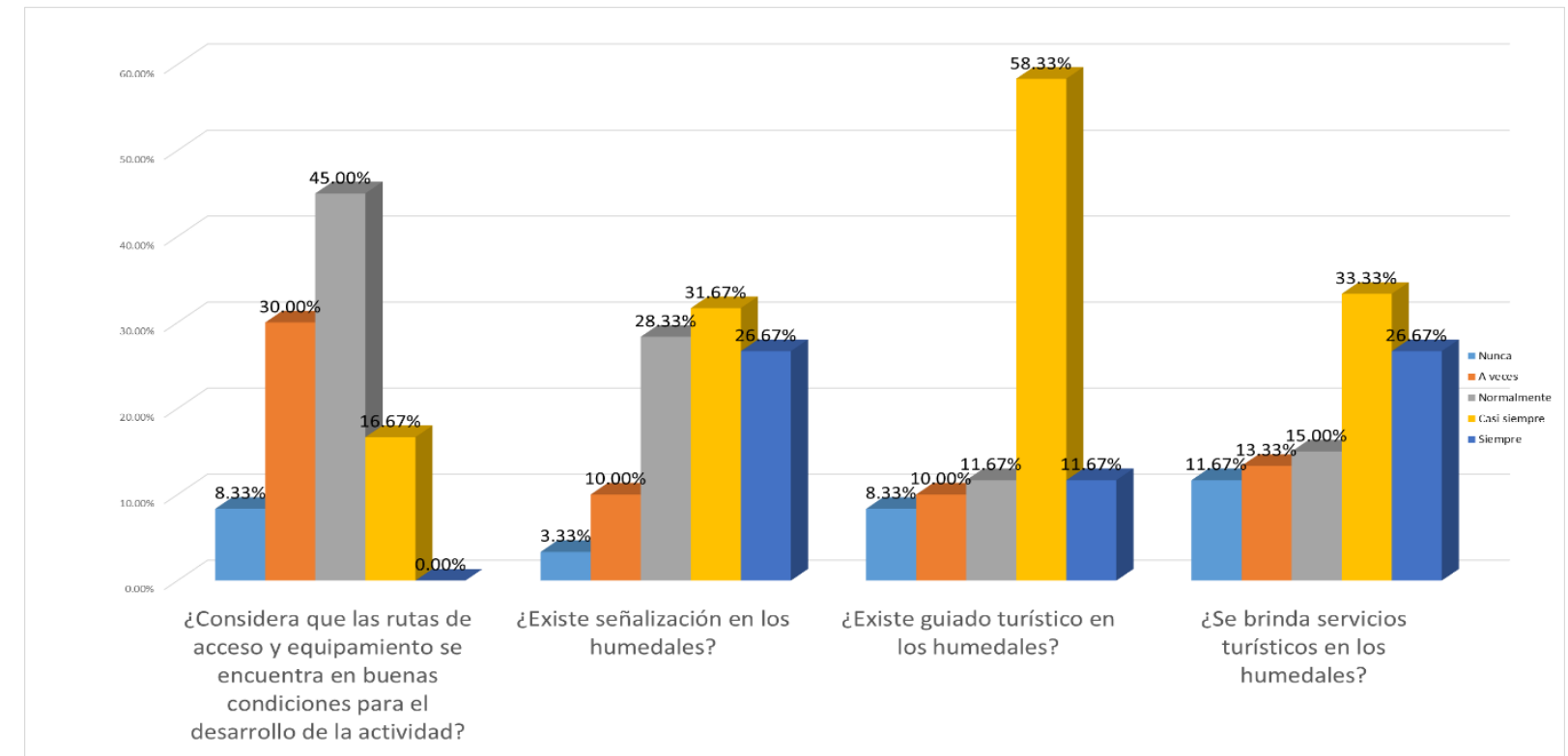

Figura 2. Frecuencias y porcentajes de los ítems correspondientes a la subcategoría rutas de avistamiento de aves para el desarrollo del turismo de avistamiento de aves en los humedales de Lima 2019.

En la subcategoría beneficios de la localidad encontramos que el $30.00 \%$ de los encuestados consideran que el desarrollo del turismo de avistamiento de aves casi siempre genera ingresos económicos en favor de la localidad, también un $45 \%$ que el desarrollo del turismo de avistamiento de aves siempre mejora la calidad de vida de los habitantes de la localidad, un $35 \%$ considera que siempre proteger la biodiversidad de los humedales contribuye con el desarrollo del turismo, también un 50\% considera siempre que tiene conocimiento de la importancia de los humedales, un 30\% considera que normalmente el desarrollo del turismo de avistamiento de aves genera puestos de trabajo y un $28.33 \%$ indican que normalmente hay inversión para mejorar la actividad turística en los humedales. Según los resultados de las encuestas podemos apreciar que la subcategoría de beneficios para la localidad, tanto los pobladores y trabajadores de los humedales tienen conocimiento de la importancia que tiene el desarrollo de la actividad turística de avistamiento de aves, y por lo tanto los entes involucrados deben invertir ya que garantiza una mejora de calidad de vida e ingresos económicos beneficiando a todas las partes involucradas, pero se aprecia que no hay una debida inversión, y la actividad turística no genera puestos de trabajo. 


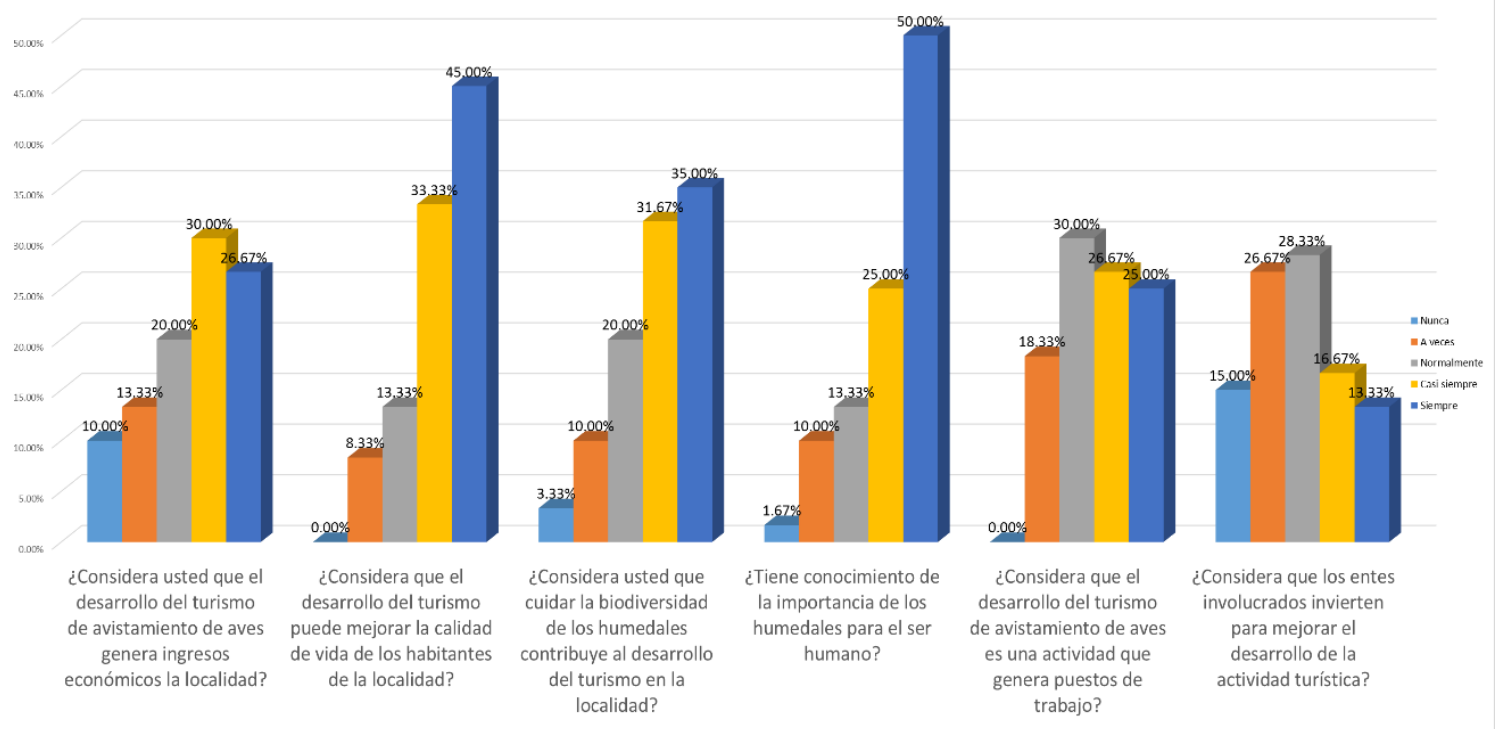

Figura 3. Frecuencias y porcentajes de los ítems correspondientes a la subcategoría beneficios para la localidad que genera el desarrollo del turismo de avistamiento de aves en los humedales de Lima 2019.

En la subcategoría de conservación de la biodiversidad encontramos que el $40 \%$ de los encuestados indican que siempre es importante la educación ambiental para cuidar los humedales, un $41.67 \%$ considera que casi siempre se realizan programas dirigidas a empresas ubicadas alrededor del humedal, un $36.67 \%$ considera que casi siempre brindan guiados turísticos dirigido a escolares, un 33.33\% normalmente ha asistido a charlas de educación ambiental y un $33.33 \%$ considera que casi siempre el turismo de avistamiento de aves contribuye en la protección del humedal. Según los resultados de las encuestas podemos apreciar que la subcategoría de conservación de la biodiversidad de los humedales, las personas encuestadas indican que es necesario implementar más programas y charlas de educación ambiental ya que contribuye con la protección del humedal, así como también incentivar el desarrollo de la actividad turística responsable para proteger el humedal.

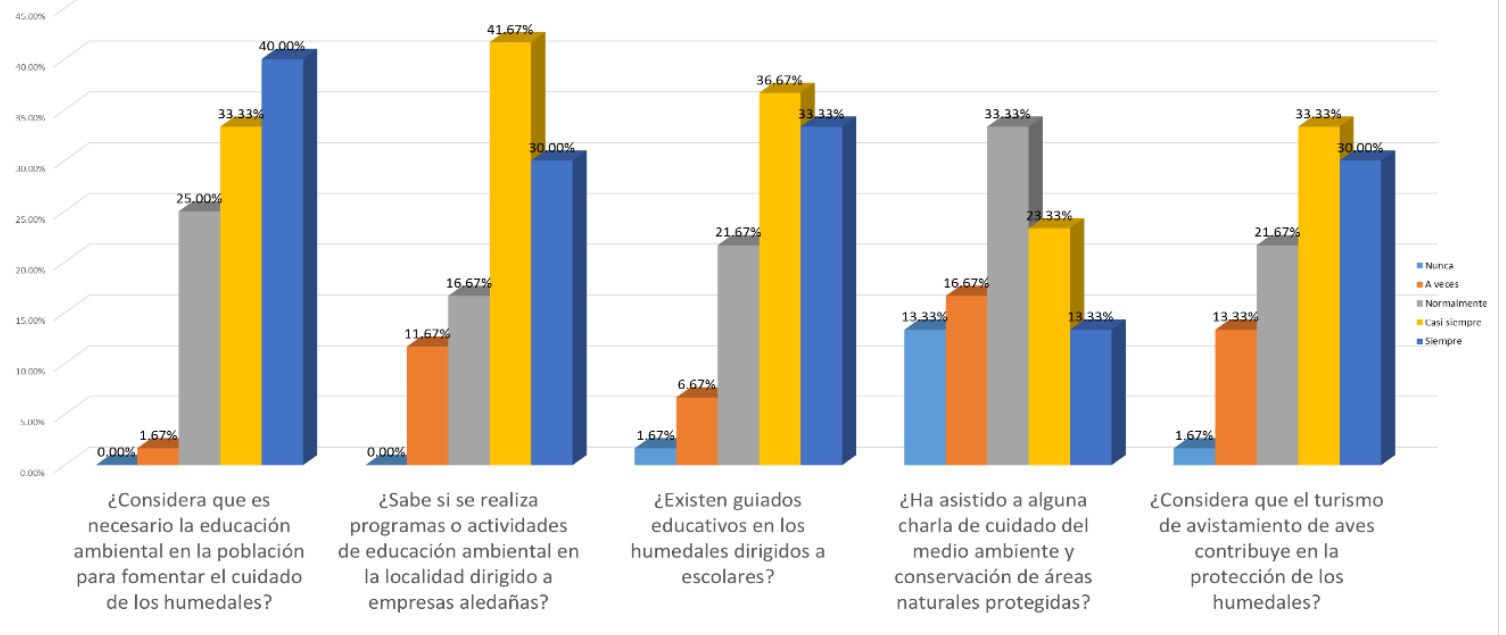

Figura 4. Frecuencias y porcentajes de los ítems correspondientes a la subcategoría conservación de la biodiversidad para el desarrollo del turismo de avistamiento de aves en los humedales de Lima 2019. 
Referente al flujo ecoturístico, Un $41.67 \%$ considera que en la actualidad los humedales son un atractivo turístico, un $36.67 \%$ indica que siempre los humedales son atractivos para realizar avistamiento de aves, un $28.33 \%$ indica que los humedales son visitados casi siempre por turistas extranjeros y un 30\% indico que casi siempre son visitados por turistas nacionales. Podemos apreciar que la subcategoría de flujo ecoturístico, en la actualidad los humedales si son considerados como atractivos turísticos, y si se practica el avistamiento de aves tanto para turistas extranjeros y nacionales, pero también podemos apreciar que normalmente visitan turistas que no realizan avistamiento de aves, más se trabaja haciendo recorridos para escolares y universidades.

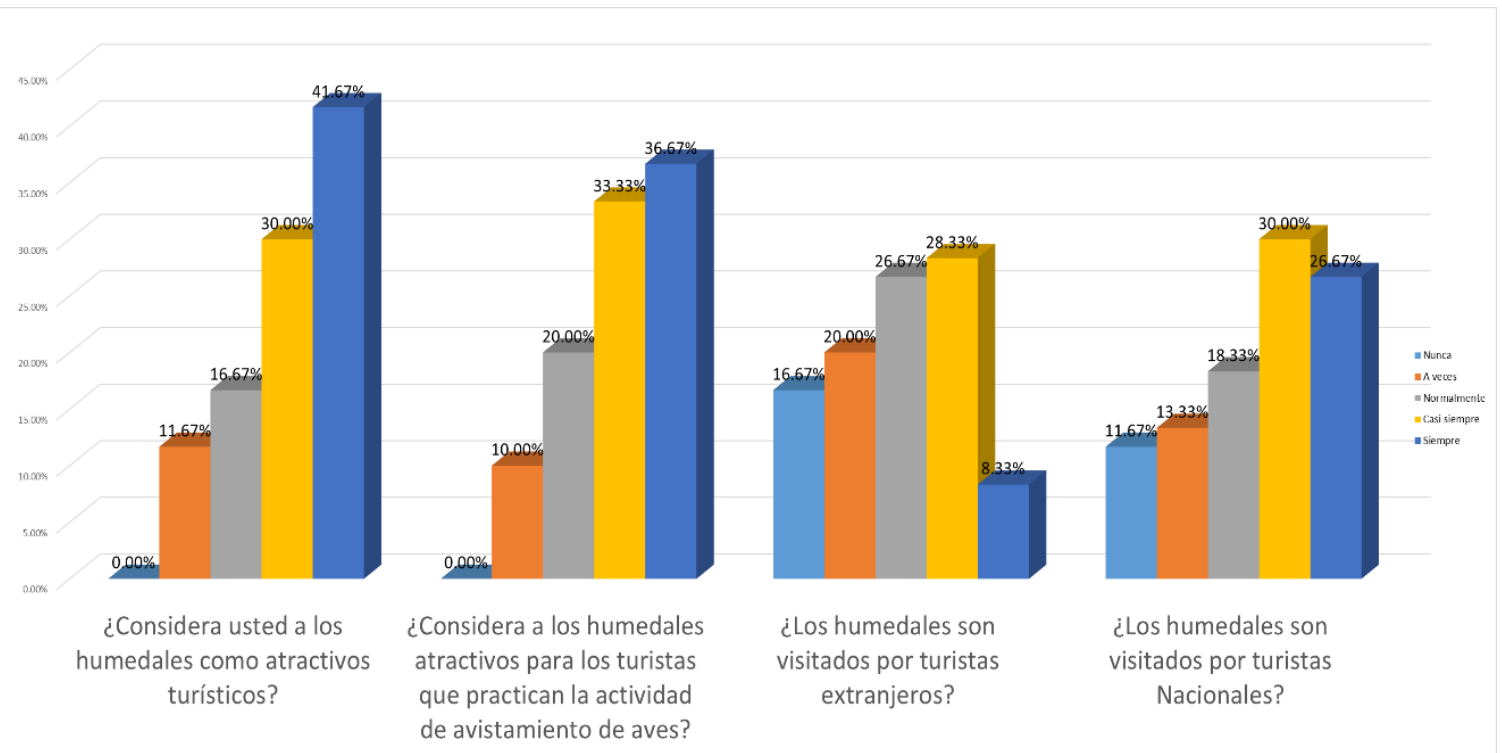

Figura 5. Frecuencias y porcentajes de los ítems correspondientes a la subcategoría flujo ecoturístico en el desarrollo del turismo de avistamiento de aves en los humedales de Lima 2019.

Finalmente encontramos dos puntos críticos gracias a nuestro cuadro de Pareto

\section{Tabla 1}

Cuadro de Pareto categoría observación de aves y desarrollo ecoturístico.

\begin{tabular}{|c|c|c|c|c|}
\hline Ítem & Puntaje & $\%$ & Acumulativo & $20.00 \%$ \\
\hline $\begin{array}{l}3 \text { ¿Considera que la infraestructura aplicada cuenta con alta } \\
\text { tecnología? }\end{array}$ & & $7.92 \%$ & $7.92 \%$ & $20 \%$ \\
\hline $\begin{array}{l}\text { 4. ¿Considera que los entes involucrados invierten en } \\
\text { infraestructura? }\end{array}$ & & $7.92 \%$ & $15.84 \%$ & $20 \%$ \\
\hline $\begin{array}{l}\text { 1. ¿Considera que los humedales cuentan con una infraestructura } \\
\text { adecuada para realizar el turismo de avistamiento de aves? }\end{array}$ & & $7.77 \%$ & $23.61 \%$ & $20 \%$ \\
\hline $\begin{array}{l}\text { 5. ¿Considera que las rutas de acceso y equipamiento se encuentra } \\
\text { en buenas condiciones para el desarrollo de la actividad? }\end{array}$ & & $7.33 \%$ & $30.94 \%$ & $20 \%$ \\
\hline
\end{tabular}

Fuente: elaboración propia 
Según las encuestas realizados podemos determinar que tenemos dos puntos críticos, los cuales son que no existe una implementación y aplicación de tecnología en la infraestructura de los humedales, se debería planificar mejores infraestructura para el desarrollo de la actividad turística y así satisfacer los requerimientos de los visitantes, también los encuestados consideran que no existe una inversión adecuada por parte de los entes involucrados para el mejor desarrollo del turismo de avistamiento de aves. También se aprecia que los pobladores tienen conocimiento de la importancia de los humedales, indican que si es necesario la educación ambiental para conservar los humedales para que se desarrolle mejor la actividad turística generando ingresos que beneficie a la población generando una mejor calidad de vida.

Para los datos cualitativos se realizaron entrevistas a 3 trabajadores cuyas preguntas según las subcategorías fueron: ¿Qué aspectos y características considera que debe tener una infraestructura dentro de los humedales para que se desarrolle el turismo de avistamiento de aves? ¿Qué características debe tener las rutas de acceso en los humedales? ¿Qué tipo de servicios Turísticos se podría brindar en los humedales? ¿Por qué considera que el desarrollo del turismo de avistamiento de aves es importante para mejorar la calidad de vida de la localidad y por ende los entes involucrados deben de invertir? ¿Para usted por qué es necesario fomentar la educación ambiental en los pobladores a través del turismo de avistamiento de aves? ¿Qué programas o actividades de educación ambiental realizadas por las municipalidades conoce? y ¿Qué características posee los humedales de lima que los hace atractivos a los turistas extranjeros y nacionales para desarrollar el turismo de avistamiento de aves? Obteniendo como resultado para la subcategoría de infraestructura que el material de construcción que se utilice debe ser amigable con el medio ambiente, que no genere impacto negativo con el suelo y visual ya que las aves pueden sentirse estresadas, lo importante es mantener el ciclo natural, se puede utilizar madera o mambú que ayuda a proteger la flora y fauna del humedal. En la actualidad se puede ir mejorando, todavía hay ciertas partes en el humedal que genera un cierto impacto en las aves ya que concurren autos y algunas invasiones. Se puede implementar tecnología sostenible, no se puede usar otro tipo de tecnología ya que impactaría negativamente con las aves, es por ello que la oficina administrativa se alquila en otro local. En cuanto a inversión, se espera que lo que se dio el año pasado, sea permanente, ya que los entes involucrados muchas veces no invierten lo necesario para el mantenimiento del lugar, se debería contratar personal capacitado para recoger la basura, las personas dejan basura alrededor del humedal, hay una obra paralizada que es una rampa para personas discapacitadas, y otra área para oficinas, se espera la decisión de SERNANP para continuar con la obra. También se espera que la universidad Científica del sur y algunos corrales no sigan invadiendo parte del humedal.

Para la subcategoría rutas avistamiento de aves la municipalidad apoyo con el tema del alimentador del metropolitano al implementar el paradero Pantanos de Villa, de ese modo las personas puedan llegar más rápido y seguros, pero al ubicarse en una avenida sin número, falta más información, falta inversión para colocar letreros como a 500 metros o 300 metros para las personas que vienen independientemente se puedan ubicar, no existe en la ruta del humedal esos letreros y es básico. Dentro del humedal si existe señalización, se da también un mapa del lugar a los visitantes para que no se pierdan, también indicaron que dentro del humedal no se puede colocar tantos letreros para evitar la agresión visual, solo en lugares estratégicos de ubicación. Falta inversión para renovar servicios, a veces se dan paseos en bote, en kayaks, programas educación ambiental, servicio de guiado, talleres de artesanía y torres de avistamiento de aves, 
juegos lúdicos, se podría implementar paseo de caballo y otras actividades, pero no hay una inversión adecuada por parte de la municipalidad, por ello se requiere voluntariados, actividades donde participen alumnos de colegios, universidades y vecinos de la zona.

Para la subcategoría beneficios para la localidad, no se genera muchos ingresos, los ingresos solo es para el mantenimiento del lugar, para que haya más ingresos o beneficios los guías deberían ser locales no extranjeros, existe inversión por ello se puede mantener el lugar, pero no se invierte más. Las personas de las zonas realizan educación ambiental, el humedal si contribuye con el desarrollo del turismo, y este tipo de turismo si puede generar puestos de trabajo, cualquier tipo de actividad turística tiene potencial para apoyar y beneficiar a la sociedad. A los jóvenes que vienen se les trasmite el mensaje en defensa del medio ambiente, y se debe identificar el mecanismo de cómo hacer llegar el mensaje a los pobladores y visitantes, hay personas que hacen voluntariado, espectáculo de títeres, a veces nos llaman para dar charlas en universidades o colegios de la zona, también se participa en ferias.

Referente a la subcategoría conservación de la biodiversidad la educación ambiental es lo básico, no es una opción, es un deber, el avistamiento de aves ayuda en la protección de los humedales, de esa manera si se puede generar economía, hay gerencias en Lima que hacen programas de observación de aves, piden drones, binoculares, se tiene programas que fomentan la integración, vienen personas a realizar estudios de forma continua, se brinda información a los pobladores y visitantes, se les crea un hábito como reciclaje, las botella de plástico están prohibido, se le explica la importancia del lugar, las virtudes, y las amenazas que existe. Se realizan charlas, tanto a estudiantes como a pobladores donde se recalca la importancia del humedal.

Para la subcategoría flujo ecoturístico Pantanos de villa es el lugar más cercano para los turistas para realizar avistamiento de aves, ya que por lo general en Lima se quedan uno o dos días y esas aves ya no las verán en la sierra o selva, es un punto interesante, vienen con agencias, solos, también hay turistas nacionales observadores de aves de distintas universidades, hay concursos internacionales que consiste en los países donde se observa aves la mayor cantidad en un día, hemos quedado en tercer lugar, algunas veces si hemos quedado en primer lugar, aun así la población de observación de aves que viene al humedal es pequeña.

En los humedales lo visitan extranjeros de Francia, Inglaterra, personas de edad que les gusta la naturaleza, sacerdotes, monjas, escolares que vienen como parte de su formación escolar, personas que realizan trabajos científicos, académicos, personas que hacen voluntariado porque son requisitos para titularse en sus universidades, parejas, visitas de fotógrafos.

\section{Promoción del turismo ornitológico}

Según los resultados de la investigación los colegios es la población que más visita a los humedales, es por ello que la propuesta es promocionar el turismo ornitológico en los colegios de Lima, para sensibilizar a los jóvenes estudiantes y fomentar su conservación, además de promocionar las actividades a través de redes sociales con la finalidad de que más turistas y visitantes deseen realizar turismo ornitológico. 


\section{Objetivo 1:}

Definir rutas estratégicas en el humedal para realizar el turismo ornitológico, obtener los equipos necesarios y contratar guías expertos en turismo ornitológico.

\section{Actividades}

- Definir rutas para realizar el turismo ornitológico en los humedales.

- $\quad$ Implementar de ruta de avistamiento de aves.

- Definir y colocar carteles de información en puntos estratégicos en los humedales.

- Diseñar guías físicas con las aves migratorias que se puedan observar en los humedales.

- $\quad$ Obtener cotizaciones para la compra de binoculares y cámaras fotográficas.

- Contratar guías locales expertos en turismo ornitológico.

- Capacitación a los guías contratados

- $\quad$ Supervisar el proyecto

\section{Objetivo 2:}

Fomentar el turismo ornitológico en los colegios, a escolares de tercero, cuarto y quinto de secundaria a través de charlas y circuitos ornitológicos en los humedales.

\section{Actividades}

- $\quad$ Reunión con las entidades educativas de la zona para presentar el proyecto de turismo ornitológico.

- $\quad$ Elaboración de folletos y materia didáctico para la Charla.

- Charlas y capacitación en turismo ornitológico a los estudiantes.

- $\quad$ Circuito peatonal ornitológico en los humedales.

- $\quad$ Sorteo de entrada doble al cine por participación didáctica de los escolares.

- Realizar video promocional.

- $\quad$ Creación de una página Facebook y una página web.

\section{Objetivo 3:}

Monitorear el plan de desarrollo, midiendo la satisfacción de los escolares luego de haber recibido las charlas y el recorrido turístico en los humedales mediante encuestas y una charla para compartir experiencias y opiniones.

\section{Actividades:}

- $\quad$ Diseño de encuesta para percibir la satisfacción de los escolares.

- $\quad$ Impresión de encuestas.

- $\quad$ Informe del desarrollo de la actividad turística.

- $\quad$ Charla participativa de opiniones y experiencias de los escolares. 


\section{Conclusiones}

En la actualidad existe poca información de los beneficios que puede traer el desarrollo del turismo ornitológico, es por ello que existe poca inversión para la conservación de los humedales, es por ello que se diseñó estrategias y un presupuesto para mejorar la infraestructura de los humedales teniendo como ejemplo de estudio los Pantanos de Villa y los humedales de Ventanilla, en el cual se definió un circuito peatonal exclusivo para realizar turismo ornitológico dentro de los humedales, con ayuda de un experto para evitar generar impactar de forma negativa en las aves a observar, con esta propuesta los visitantes podrán observar las aves con mayor facilidad.

Debido a la poca inversión no cuentan con los equipos necesarios para realizar la actividad ornitológica, se da oportunidad a pocos guías locales es por ello que no existe un beneficio económico, por ello se definió obtener el equipo necesario para poder realizar este tipo de turismo, es importante obtener binoculares, cámaras fotográficas y unas guías físicas las cuales se diseñarán colocando fotos e información necesaria para que los visitantes puedan obtener un mayor conocimiento e identificar a las aves que están observando, a la vez contar con guías locales expertos en turismo ornitológico, con ello los humedales quedaran actos para ser productos donde se realice esta actividad ornitológica.

Para fomentar el turismo ornitológico se diseñó un plan de promoción dirigido escolares ya que los colegios es la población que más visitan los humedales, el plan consiste en brindar charlas las cuales brinden información acerca del turismo ornitológico y a la vez concientizar e incentivar a los jóvenes estudiantes a conservar la naturaleza y crear hábitos de sostenibilidad, también estará incluido el recorrido peatonal para que puedan realizar este tipo de turismo, este plan será monitoreado para que se pueda desarrollar de la mejor manera.

La propuesta se publicará en redes sociales en los cuales se subirán videos, fotografías, experiencias con la finalidad de promocionar este tipo de turismo en Lima y las diversas empresas turísticas puedan implementar en sus servicios este tipo de turismo alternativo, de esa manera el avistamiento de aves será una actividad que seguirá en crecimiento ya que cada vez hay más visitantes y turistas interesados en observar aves.

\section{Bibliografía}

Altamirano, S. (11 de Diciembre de 2015). Determinación de la avifauna de la isla Santay para proponer puntos estratégicos para el avistamiento de aves. . Obtenido de http://repositorio.ug.edu.ec/bitstream/redug/8707/1/Sheyla\%20Altamirano\%20Flores $\% 20$ TESIS.pdf

Bohorquez, D. (2017). Turismo ornitológico en los humedales del distrito de Ite como mecanismo de sensibilidad ambiental de sus pobladores en el año 2016. tacna, Perú: Universidad Privada de Tacna. Obtenido de http://repositorio.upt.edu.pe/bitstream/UPT/241/1/Bohorquez-P\%C3\%A9rez-DianaFrancis.pdf

Boullon, R. (2006). Planificación del espacio turístico. En R. Boullon. Mexico D. F., Mexico: Trillas. Obtenido de https://www.entornoturistico.com/wp- 
content/uploads/2017/02/Planificaci\%C3\%B3n-del-espacio-tur\%C3\%ADstico-deRoberto-C.-Boullon-PDF.pdf.

Brundtland, G. (1987). Nuestro futuro común. Unesco. (C. G. Gutierrez, Productor) Obtenido de http://www.unesco.org/new/fileadmin/MULTIMEDIA/FIELD/Havana/pdf/Cap3.pdf

Criales, A. (2016). Modelo de gestión para implementar infraestructura turística en los humedales de la costa central del Perú. Lima, Perú: Universidad Peruana Cayetano Heredia. Obtenido de http://repositorio.upch.edu.pe/bitstream/handle/upch/3593/Modelo_CrialesJohnson_Astri d.pdf? sequence $=1 \&$ is Allowed $=\mathrm{y}$.

Figueroa, E., \& Javier., S. (2003). Globalización y biodiversidad. En E. Figueroa, \& S. Javier. Santiago de Chile, Chile: Universitaria. Obtenido de https://books.google.com.pe/books?id=ayHuSWQbv1wC\&pg=PA4\&dq=Figueroa+Euge nio,+Simonetti+Javier++(2003)+Globalizaci\%C3\%B3n+y+B.

Hernandez, L., Pachote, R., \& Velásquez, M. (2017). Análisis del producto Turístico de avistamiento de aves en Bogotá región y sus posibilidades de desarrollo. Bogota D.C, Colombia: Universitaria Agustiniana. Obtenido de http://repositorio.uniagustiniana.edu.co/bitstream/123456789/288/1/HernandezLizarazoLauraCristina-2018.pdf

Hurtado, J. (2000). Metodologia de la investigación. En J. Hurtado. Caracas, Venezuela: Fundación Sypal. Obtenido de https://es.scribd.com/doc/125943460/hurtado-de-barrerajacqueline-metodologia-de-investigacion-holistica-pdf.

Lopez, j. (2008). El turismo ornitológico en el mercado del Postfordismo, una aproximación teórica conceptual-España. Revistas UM, 86. Obtenido de https://revistas.um.es/turismo/article/view/25001/24291

MINCETUR. (2011). Turismo guía para la formulación de proyectos de inversión exitosos. Obtenido de Turismo guia para la formulación de proyectos de inversión exitosos: https://www.mef.gob.pe/contenidos/inv_publica/docs/instrumentos_metod/turismo/Guia_ de_turismo.pdf.

PROMPERU. (2017). Perfil del vacacionista nacional 2017. Obtenido de https://www.promperu.gob.pe/TurismoIN/sitio/VisorDocumentos?titulo=Perfil\%20del\% 20Vacacionista\%20Nacional\%202017\&url= /Uploads/perfiles_vacac_nac/1039/PVN17. pdf\&nombObjeto=PerfVacacionis

Ramsar. (2006). Manual de la Convencion de Ramsar $4^{\circ}$ edicion. Obtenido de Manual de la Convencion de Ramsar $4^{\circ}$ edicion: https://www.ramsar.org/sites/default/files/documents/pdf/lib/lib_manual2006s.pdf.

Turismo, O. M. (2002). UNWTO Ecoturismo $y$ areas protegidas. Obtenido de http://www2.unwto.org/es/content/ecoturismo-y-areas-protegidas

Turismo, O. M. (19 de febrero de 2011). Desarrollo sostenible del turismo. Obtenido de Desarrollo sostenible del turismo: https://sdt.unwto.org/sites/all/files/pdf/e-bul19sp.pdf

Turismo, O. M. (2018). UNWTO ¿Por qué el Turismo? Obtenido de https://www2.unwto.org/es/content/por-que-el-turismo. 